\title{
Knowledge, attitude and behavior towards COVID-19 among the Turkish healthcare workers
}

\author{
Yasin Uzuntarla ${ }^{1}$, Sumeyra Ceyhan ${ }^{2}$ \\ ${ }^{1}$ Department of Health Management, Gülhane Training and Research Hospital, Ankara, Turkey \\ ${ }^{2}$ Department of Health Management and Organization, Health Services Vocational School, Bingol University, Bingol, Turkey
}

Received: 2020-09-30.

Accepted: $2020-10-24$

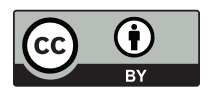

This work is licensed under a

Creative Commons Attribution 4.0 International License

J Clin Med Kaz 2020; 6(60):93-98

Corresponding author:

Yasin Uzuntarla.

E-mail: yasinuzuntarla@gmail.com;

ORCID: 0000-0002-5021-3763

\section{Abstract}

Aim: Coronavirus disease 2019 (COVID-19) cases and the number of deaths linked to this disease have been increasing day by day, turning into a global health problem. Healthcare workers play a key role in the fight against COVID-19. It is aimed to determine the level of knowledge, attitude and behavior of Turkish healthcare workers towards COVID-19.

Material and methods: This cross-sectional study was carried out with healthcare workers working in two state hospitals in Ankara and Bingol, Turkey. The participation rate in the survey was $76 \%$, and the survey was completed by 836 healthcare workers.

Results: $56.3 \%$ of the participants are women, $64.9 \%$ are married and $44.9 \%$ are nurses. It was found that $85 \%$ of the healthcare workers had a medium level of knowledge, $87 \%$ had a high level of attitude and $89 \%$ had a high level of behavior. In addition, a significant difference was found in the knowledge level of healthcare workers according to monthly income level and profession, and their behaviors by age $(p<0.05)$.

Conclusion: There is a significant positive correlation between knowledge, attitude and behavior towards COVID-19. Healthcare workers' training curricula and in-service training should provide information that will improve their knowledge, attitudes and behaviour towards COVID-19.

Key words: attitude, behavior, COVID-19, healthcare workers, knowledge

\section{Introduction}

Pandemic is a common name given to outbreaks that spread and affect a very wide area in more than one country or continent around the world. In general terms, three criteria are required for a disease to be named as a pandemic. These criteria are that it is a new virus; it can easily be passed on to humans and can be easily and continuously transmitted from person to person $[1,2]$.

Following the reporting of cases of pneumonia, whose etiology was unknown, in Wuhan, China in December 2019, a new type of coronavirus that had not previously been seen in humans was identified by the World Health Organization (WHO). Although the majority of cases were in China, it was also seen in individuals who traveled to China in Japan, Hong Kong, Taiwan, South Korea, Thailand, USA, Vietnam and Singapore. Its spread in society and its appearance among healthcare workers is important evidence of humanto-human transition. On 11 March 2020, COVID-19 was declared a pandemic by the WHO [3,4].

COVID-19 poses a serious public health threat. Older adults and people with pre-existing medical conditions such as diabetes, hypertension, heart disease, chronic lung disease, and obesity are at higher risk of complications and serious illness [5]. The most common symptoms of COVID-19 are fever, tiredness, shortness of breath, and dry cough. Some patients may experience pain and tingling, nasal congestion, runny nose, sore throat or diarrhea [6]. Symptoms usually begin a few days after a person is infected with the virus, and most cases occur about 3-7 days after exposure. In some people, it may take up to 14 days for symptoms to appear. Some people become infected but don't develop any symptoms, and they don't feel bad either. The disease is mainly transmitted from infected people. It is spread by droplets emitted by infected individuals during actions such as coughing, sneezing, speaking, and laughing. $[3,7,8]$.

The fact that there are more than 25 million people diagnosed with COVID -19 and nearly 860 thousand deaths worldwide indicates that the disease is a serious problem [9]. Unfortunately, the vaccine and its treatment have not 
been found yet, and it makes it difficult to fight the disease and to make a clear prediction. Despite this, healthcare workers play a key role in combating the pandemic by providing health services at risky locations under these severe and difficult conditions due to their professional obligations [10].

It has been reported that the studies on COVID-19 are insufficient, and research should play a major role in controlling its spread [11]. It is seen that the studies in this area are very limited in healthcare workers who are actively fighting against COVID-19. Approximately $6 \%$ of healthcare workers in Turkey, $10.4 \%$ in Italy, $10 \%$ in the USA and $22.2 \%$ in Brazil have been reported to have COVID-19 [12-15]. Understanding knowledge, attitudes, and behaviors of healthcare workers towards COVID-19 could reduce and prevent spread among them.

In light of the research that the level of knowledge directly affects attitudes and behavior, it is important to identify the level of knowledge of healthcare workers and to develop action plans for them $[16,17]$. Studies have been conducted to determine the knowledge, attitudes, and behaviors of healthcare professionals in different countries towards COVID-19 [8,15]. Although nearly a year has passed since the outbreak, failure to carry out such a study in Turkey is a serious deficiency. The results of this research will support health politicians, decision-makers and professional organizations in their decision-making. With this study, it is aimed to determine the level of knowledge, attitude and behavior of Turkish healthcare workers towards COVID-19.

\section{Material and methods}

The cross-sectional study was conducted among healthcare workers working in two state hospitals in Ankara and Bingöl provinces, Turkey between May and June 2020. Ankara, the capital of Turkey, is centrally located. Bingöl is a rural town situated in the eastern region. The hospitals were chosen by the authors for ease of access to the participants. Hospitals are secondary health institutions. Due to the coronavirus measures, employees were reached through an online data-based survey method instead of face-to-face interview technique. However, some personnel did not participate in the study due to annual leave, illness, and not wanting to fill out the questionnaire. The participation rate in the survey was $76 \%$ and the research was completed in line with the ethical principles of the Declaration of Helsinki with 836 healthcare personnel who voluntarily participated in the study. The necessary permissions were obtained from Bingöl University Ethics Committee (dated $13 / 05 / 2020$ and numbered $92342550 / 044$ ) for this study.

\section{Questionnaire}

In the research, a questionnaire form developed by Srichan et al. to determine the knowledge, attitude and behavior towards COVID -19 was used [18]. After receiving permission from the author to utilize this questionnaire, the English version of the questionnaire was translated from English to Turkish by three people with an advanced level of English. The resulting questionnaire was translated back into English by a total of three people, one of whom was a linguist and the other two were native English. At the last stage, the semantic difference was prevented by ensuring the equality of forms in both languages [19]. Reliability indicates whether all items in a measurement tool are homogeneous [20]. In this study, Cronbach's Alpha (CA) coefficient was calculated to test the internal consistency of the questionnaire form.

The questionnaire form used in the study consists of 4 parts and 38 questions.

\section{Sociodemographic characteristics}

It consists of eight questions created by the authors as a result of the literature review such as gender, age, marital status, place of residence, monthly income, occupation, number of members in the family, avoidance of entering the collective environment due to work, and experiencing death anxiety due to coronavirus.

\section{Knowledge regarding COVID-19 prevention and control}

There are 10 questions to determine the knowledge levels of the participants about Covid-19. 5 of the questions contain negative and 5 have positive statements. It is calculated by giving " 0 " points for wrong answers and " 1 " points for correct answers. Accordingly, those who score 0-5 are considered to have a poor knowledge level, those who score 6-8 are considered to be moderate, and those who score 9-10 are considered to be good [18]. Some sample statements in this section are as follows: "COVID-19 is a close-contact communicable disease", "COVID-19 is caused by having unhealthy food in everyday", and "Children are the highest vulnerable for COVID-19 infection."

\section{Attitudes toward COVID-19 prevention and control}

To determine the attitudes of the participants towards COVID-19, there are 10 questions in a five-point Likert type. 5 of the questions contain negative attitude statements and 5 of them contain positive attitudes. It is scored as 1 point for "Totally disagree" and 5 points for "Totally agree". Those who score below 26 are considered to be poor, those who score between $26-40$ points as a moderate, and those who score 41 and above are considered to have a good attitude [18]. Sample statements in this section are as follows: "COVID-19 is serious disease", "Stay at home is a good way to prevent and control COVID-19" and "Everyone needs to responsible to prevent and control COVID-19, not just a doctor."

\section{Behaviors toward COVID-19 prevention and control}

There are 10 questions regarding the respondent behaviors of the participants towards COVID-19. The questions were scored in 3-Likert type with 3 points for "always", 2 points for "sometimes" and 1 point for "never". The behavior level of those below 16 points is considered to be poor, those who score between 16-24 points are considered to have moderate, and those who score 25 and above are considered to have a good response behavior [18]. Sample statements in this section are as follows: "Frequency of self check on signs and symptoms related to COVID-19 disease", "Frequency of wearing a surgical mask" and "Frequency of use soap while washing hands."

In the original study, the knowledge, attitude and behavior of the people according to the correct answers they gave to the questionnaire were categorized as poor, moderate and good. While the high level indicates that the knowledge, attitude and behavior of individuals towards COVID-19 is sufficient, the low level indicates that it is insufficient [18].

\section{Statistical analysis}

The analysis of the research data was done with the SPSS (Version 21, Chicago IL, USA) statistics program. The arithmetic mean, standard deviation, and frequency analysis were used to analyze descriptive statistics. Whether the data show normal Journal of Clinical Medicine of Kazakhstan: Volume 6, Number 60, Issue 2020 
distribution or not was determined by the kurtosis and skewness values. It was observed that the Skewness and Kurtosis values were in the \pm 2 range, showing a normal distribution [21]. Due to the normal distribution of the data, the Independent Samples T-Test was used to compare two independent groups, One Way ANOVA to compare three or more groups, Post Hoc Tukey Test to determine the differences between groups, and Pearson Correlation analysis to determine the relationships between knowledge, attitude and behavior. Statistically, a value of $p<0.05$ was considered significant.

\section{Results}

Out of $836,56.3 \%$ of the participants are women, $64.9 \%$ are married and $44.9 \%$ are nurses. The age range is (20-65), and the mean age is $36.14 \pm 8.55$. The sociodemographic characteristics of the participants are presented in Table 1.

\section{Table 1}

Sociodemographic characteristics of the participants

\begin{tabular}{|c|c|c|}
\hline Variables & $\mathrm{n}$ & $\%$ \\
\hline \multicolumn{3}{|l|}{ Sex } \\
\hline Female & 472 & 56.3 \\
\hline Male & 366 & 43.7 \\
\hline \multicolumn{3}{|l|}{ Age groups (year) } \\
\hline$\leq 30$ & 250 & 29.8 \\
\hline $31-40$ & 322 & 38.4 \\
\hline$\geq 41$ & 266 & 31.7 \\
\hline \multicolumn{3}{|l|}{ Marital status } \\
\hline Married & 544 & 64.9 \\
\hline Bachelor & 294 & 35.1 \\
\hline \multicolumn{3}{|l|}{ Place of residence } \\
\hline Province & 682 & \begin{tabular}{|l|l|}
81.4 \\
\end{tabular} \\
\hline District & 132 & 15.8 \\
\hline Village & 24 & 2.9 \\
\hline \multicolumn{3}{|l|}{ Montly income } \\
\hline$\leq 5000 \mathrm{TL}$ & 292 & 34.8 \\
\hline 5001-8000 Turkish Liras & 286 & 34.1 \\
\hline$\geq 8001 \mathrm{TL}$ & 260 & 31.0 \\
\hline \multicolumn{3}{|l|}{ Occupation } \\
\hline Physician & 168 & 20.0 \\
\hline Nurse & 376 & 44.9 \\
\hline Health technician & 162 & 19.3 \\
\hline Nonclinical staff & 132 & 15.8 \\
\hline \multicolumn{3}{|l|}{ Number of family member } \\
\hline $1-3$ & 422 & 50.4 \\
\hline $4-6$ & 394 & 47.0 \\
\hline$\geq 7$ & 22 & 2.6 \\
\hline
\end{tabular}

Table 2

Distribution of participants' knowledge, attitudes and behaviors towards COVID-19

\begin{tabular}{|l|l|l|l|l|l|c|}
\hline \multirow{2}{*}{} & \multicolumn{2}{l|}{ Poor } & \multicolumn{2}{l|}{ Moderate } & \multicolumn{2}{l|}{ Good } \\
\cline { 2 - 8 } & $\mathrm{n}$ & $\%$ & $\mathrm{n}$ & $\%$ & $\mathrm{n}$ & $\%$ \\
\hline Knowledge & 30 & 3.5 & 712 & 85.0 & 96 & 11.5 \\
\hline Attitude & 4 & 0.5 & 108 & 12.9 & 726 & 86.6 \\
\hline Behaviors & - & - & 96 & 11.5 & 742 & 88.5 \\
\hline
\end{tabular}

Table 3

Correlation, reliability and statistical findings of

\begin{tabular}{|l|l|l|l|l|l|l|}
\hline Variables & 1 & 2 & 3 & Mean & $\begin{array}{l}\text { Standard } \\
\text { Deviation }\end{array}$ & CA\& \\
\hline 1.Knowledge & 1 & & & 7.22 & 1.04 & 0.81 \\
\hline 2.Attitude & $0.378^{* *}$ & 1 & & 44.87 & 4.45 & 0.77 \\
\hline 3. Behavior & $0.310^{* *}$ & $0.367^{* *}$ & 1 & 26.39 & 1.65 & 0.83 \\
\hline
\end{tabular}

(**p<0.01, \&CA: Cronbach's Alpha)
With the question "Are you worried about infecting your family with the disease because you're in a public environment due to your job requirement?", it was found that $87.6 \%(n=734)$ of the participants were worried, $7.2 \%(n=60)$ were not worried, and $5.3 \%(\mathrm{n}=44)$ were undecided.

It was found that $39.1 \%(n=328)$ of the participants answered "Yes", 43.2\% (n=362) answered "No" and 17.7\% $(n=148)$ answered "Indecisive" to the question "Do you have death anxiety from coronavirus?".

When the knowledge levels of the participants about COVID-19 were examined; It was found that $85 \%(n=712)$ was at the moderate level, $11.5 \%(n=96)$ was at a good level, and $3.5 \%(n=30)$ was at a poor level. When the attitude levels were examined; It was found that $86.6 \%(n=726)$ of them had good, $12.9 \%(n=108)$ had moderate and $0.5 \%(n=4)$ had a poor attitude. When the behavioral levels of healthcare workers towards COVID-19 were examined, it was found that $88.5 \%(n=742)$ were good, $11.5 \%(n=96)$ were moderate, and no participants were at a poor level (Table 2).

Descriptive information and correlations for the questions in our study are presented in Table 3. It was found that the average score of the participants' knowledge level about COVID-19 (7.22 \pm 1.04$)$ was medium, the mean score of the attitude level $(44.87 \pm 4.45)$ was high, and the behavior level $(26.39 \pm 1.65)$ was high. It is seen that the CA coefficient is above 0.7 and it is reliable [22]. It is seen that there is a slight and significant correlation in the same direction between knowledge, attitude and response preparedness skill towards COVID-19 ( $p<0.01)$.

When the questions were examined according to sociodemographic characteristics; a statistically significant difference was found between the groups in the level of knowledge about COVID-19 according to monthly income and occupation, and behavior level by age (Table 4).

\section{Discussion}

With this study, it was aimed to determine the knowledge, attitude and behavior levels of healthcare professionals working in two state hospitals in Ankara and Bingöl, Turkey provinces towards COVID-19.

In our study, it was found that $85 \%$ of the participants had moderate knowledge, $87 \%$ had a high level of attitude, and $89 \%$ had a high level of behavior. In the study conducted by Zhang et al., it was determined that $89 \%$ of the healthcare workers in China had sufficient knowledge, $90 \%$ of them showed the high level behavior, and those who were experienced and high level of education were more positive [23]. In the study conducted in Italy by Moro et al., it was found that $57.8 \%$ of the healthcare workers had sufficient knowledge [24]. In the study conducted by Sing Gambhir et al. with dentists in India, it was found that $87 \%$ of the participants had sufficient knowledge, those with a high level of education and those working in the public sector were at a more positive level [25]. In the study conducted by Shi et al. with psychiatric hospital staff in China, it was found that $89.5 \%$ of the participants had sufficient knowledge [26]. In the study conducted by Aydin and Balci with the nurses in Turkey, it was found that $89.4 \%$ of nurses had sufficient information [27]. The study conducted by Sogut et al. [28] with midwifery students in Turkey and the study conducted by Khasawneh et al. [29] with medical students in Jordan found that a large proportion of the participants had sufficient knowledge. Our study is similar to previous studies, and it is considered that the knowledge, attitude and behavior of healthcare workers towards COVID-19 are at a good level. 
Knowledge, attitude and behavior towards COVID-19 according to sociodemographic characteristics of health personnel

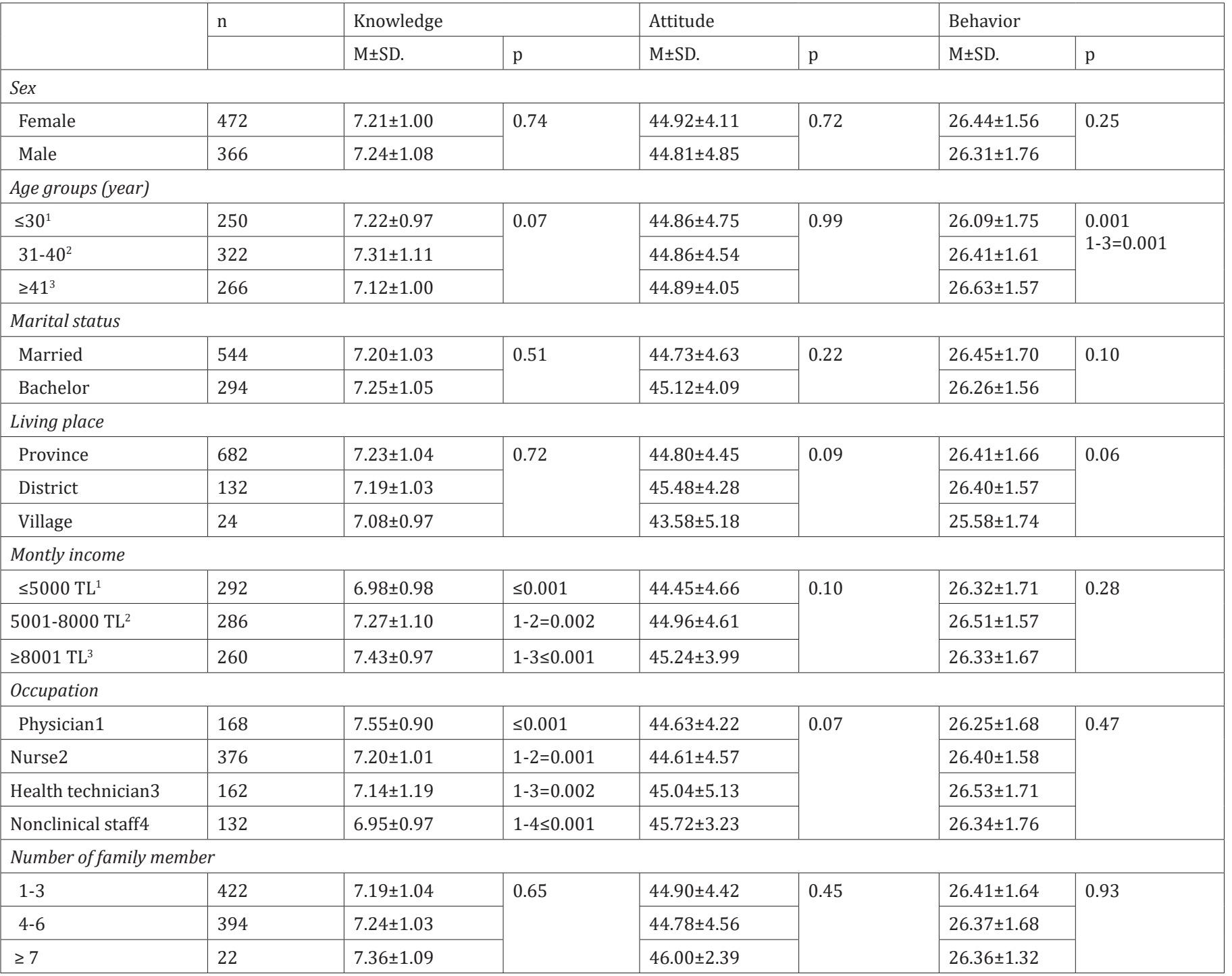

(Mean: M, Standard Deviation: SD, TL: Turkish Lira) Independent Samples T Test, One Way ANOVA, Post Hoc Tukey Test

In our study, it was found that physicians were significantly more knowledgeable than other health workers and those with high-income levels compared to those with low-income levels. In the study carried out by Bhagavathula et al. [30] with health workers, significant differences were determined by occupation and age, and in the study conducted by Kara et al. [31] with hospital pharmacists by age. In the study conducted by Alhaj et al. with neurosurgery assistants, a significant difference was observed in the level of knowledge only by location, and it was found that North America and Arabian Gulf Cooperation Council countries (Kuwait and Saudi Arabia) had more information than those in Europe [32]. Our study also found that older people behave more positively than younger ones, which is similar to the literature [33]. It is considered that the older ones have more professional experience and that their experience is effective in showing the correct behavior.

It is observed that the probability of getting COVID-19 is quite high for healthcare personnel who provide care to patients [34]. It is reported that more than 10 physicians and nurses have contracted the disease in a two-month period of care at a health centre, as well as ambulance staff [34]. As a means of protection from the disease, it is considered that taking care of distance, using masks and personal protective equipment, especially N95 masks, and applying security and antiseptic techniques will be effective $[35,36]$. In our study, it was found that $89 \%$ of healthcare workers behave appropriately.
In addition to getting caught in COVID-19; eczema due to long-term use of masks and gloves, heavy workloads, the anxiety of transmitting the disease to their families and psychological stress caused by living separately for a while are other issues that should be taken into consideration $[7,8]$. The study conducted by Duruk et al. [7] with dentists in Turkey found that more than $90 \%$ were concerned for their family and themselves, while in our study this rate was $87.6 \%$. The research results are similar to the previous ones. In similar studies [8,27], the fact that $66.7 \%$ of the healthcare workers provided care to the patient infected with the COVID-19 virus, $91.1 \%$ of them think that they are in the risky group and $62 \%$ of them do not see the workplace as safe in terms of contamination confirms that healthcare workers are right to be concerned.

The research results are limited to the hospitals where the research was conducted. It was assumed that the participants answered the questions correctly and sincerely. Multi-centered research and high participation rate are the strengths of the research.

\section{Conclusion}

As a result, the knowledge, attitudes and behaviors of Turkish healthcare professionals towards COVID-19 were determined at a positive level in our study. There is a significant positive correlation between knowledge, attitude and behavior towards COVID-19. It is a fact that training healthcare workers 
play an important role in combating infectious diseases [37], and therefore training staff for COVID-19 is very important [38]. Health workers' training curricula and in-service training should be provided with information that will improve COVID-19's knowledge, attitudes and behaviors.

Disclosures: There is no conflict of interest for all authors.
Acknowledgements: We would like to thank health personnel who participated in the research helpfully and devotedly without expecting material compensation.

Funding: None.

\section{References}

1. Last JM, editor. A Dictionary of Epidemiology. 4th ed. New York: Oxford University Press; 2001.

2. Turkish Academy of Sciences. Covid-19 Situational Assessment Report. Ankara, Turkey; Turkish Academy of Sciences Publications, TUBA Report No: 34; 2020.

3. Ozlu A, Oztas D. Learning lessons from the past in combating the novel coronavirus (Covid-19) pandemic. Ankara Med J. 2020; 2:468481. https://doi.org/10.5505/amj.2020.46547

4. World Health Organization. Coronavirus disease (COVID-19) pandemic. https://www.who.int/emergencies/diseases/novelcoronavirus-2019/ Accessed; September 23, 2020.

5. Wu JT, Leung K, Bushman M, et al. Estimating clinical severity of COVID-19 from the transmission dynamics in Wuhan, China. Nat Med. 2020; 26:1-5. https://doi.org/10.21203/rs.3.rs-17453/v1

6. Li Q, Guan X, Wu P, et al. Early transmission dynamics in Wuhan, China, of novel coronavirus-infected pneumonia. $N$ Eng $J$ Med. 2020; 382:1199-1207. https://doi.org/10.1056/NEJMoa2001316

7. Duruk G, Gumusboga ZS, Colak C. Investigation of Turkish dentists' clinical attitudes and behaviors towards the COVID-19 pandemic: A survey study. Braz Oral Res. 2020; 34: e054. https://doi.org/10.1590/1807-3107bor-2020.vol34.0054

8. Ogolodom MP, Mbaba AN, Alazigha N, Erondu OF, Egbe NO, Golden I, et al. Knowledge, attitudes and fears of healthcare workers towards the corona virus disease (COVID-19) pandemic in South-South, Nigeria. Health Sci J. 2020; 1(2):1-10.

9. World Health Organization. Coronavirus disease (COVID-19) dashboard. https://covid19.who.int/table. Accessed; September 3, 2020.

10. Orentlicher D. The physician's duty to treat during pandemics. Am J Public Health. 2018; 108(11):1459-1461. https://doi.org/10.2105/ AJPH.2018.304582

11. Wu JT, Leung K, Leung GM. Nowcasting and forecasting the potential domestic and international spread of the 2019-nCoV outbreak originating in Wuhan, China: A modelling study. The Lancet. 2020; 395:689-697. https://doi.org/10.1016/S0140-6736(20)30260-9

12. Turkish Ministry of Health. Current Status in Turkey. https://covid19.saglik.gov.tr/?lang=en-US. Accessed; September 23, 2020.

13. Istituto Superiore di Sanità Epidemia COVID-19. Sorveglianza integrata COVID-19 in Italia. https://www.epicentro.iss.it/coronavirus/ bollettino/Infografica_27aprile\%20ITA.pdf. Accessed; September 3, 2020.

14. Centers for Disease Control and Prevention. Characteristics of health care personnel with COVID-19 - United States. February 12-April 9, 2020. MMWR. 2020; 69:477-481. https://doi.org/10.15585/mmwr.mm6915e6

15. Pessa Valente E, Cruz Vaz da Costa Damásio L, Luz LS, et al. COVID-19 among health workers in Brazil: The silent wave. $J$ Glob Health. 2020; 10(1):010379. https://doi.org/10.7189/jogh.10.010379

16. Ilesanmi O, Alele FO. Knowledge, attude and perception of ebola virus disease among secondary school students in Ondo State, Nigeria, October, 2014. PLoS Curr. 2016; 8. https://doi.org/10.1371/currents.outbreaks.c04b88cd5cd03cccb99e125657eecd76

17. Janjua NZ, Razaq M, Chandir S, et al. Poor knowledge - Predictor of nonadherence to universal precautons for blood borne pathogens at frst level care facilites in Pakistan. BMC Infect Dis. 2007; 7(81):1-11. https://doi.org/10.1186/1471-2334-7-81

18. Srichan P, Apidechkul T, Tamornpark R, et al. Knowledge, attitude and preparedness to respond to the 2019 novel coronavirus (COVID-19) among the bordered population of Northern Thailand in the early period of the outbreak: A cross-sectional study. The Lancet. 2020. https://doi.org/10.2139/ssrn.3546046

19. Beaton DE, Bombardier C, Guillemin F, et al. Guidelines fort the Process of Cross-Cultural Adaptation of self-Report Measures. Spine. 2000; 25:3186-3191. https://doi.org/10.1097/00007632-200012150-00014

20. Fraenkel JR, Wallen NE, Hyun HH. How to Design and Evaluate Research in Education. 8th ed. Newyork: McGraw-Hill; 2012.

21. Pituch KA, Stevens JP. Applied Multivariate Statistics for The Social Sciences. 4th ed. New York: Routledge; 2012. https://doi. org/10.4324/9780203843130

22. Gurbuz S. AMOS ile yapısal eşitlik modellemesi. Ankara: Seçkin Publishing; 2019.

23. Zhang M, Zhou M, Tang F, et al. Knowledge, attitude and practice regarding COVID-19 among health care workers in Henan, China. $J$ Hosp Infect. 2020; 105:183-187. https://doi.org/10.1016/j.jhin.2020.04.012

24. Moro M, Vigezzi GP, Capraro M, et al. 2019-novel coronavirus survey: Knowledge and attitudes of hospital staff of a large Italian teaching hospital. Acta Biomed. 2020; 91(3-S):29-34.

25. Singh Gambhir R, Singh Dhaliwal J, Aggarwal A, et al. Covid-19: A survey on knowledge, awareness and hygiene practices among dental health professionals in an Indian scenario. Rocz Panstw Zakl Hig. 2020; 71(2):223-229. https://doi.org/10.32394/rpzh.2020.0115

26. Shi Y, Wang J, Yang Y, et al. Knowledge and attitudes of medical staff in Chinese psychiatric hospitals regarding COVID-19. Brain Behav Immun. 2020; 4:10064. https://doi.org/10.1016/j.bbih.2020.100064

27. Aydin S, Balci A. COVID-19 knowledge level research in nurses. J Surg Res. 2020; 3:198-203. https://doi.org/10.26502/jsr.10020072

28. Sogut S, Dolu I, Cangol E. The relationship between COVID-19 knowledge levels and anxiety states of midwifery students during the outbreak: A cross-sectional web-based survey. Perspect Psychiatr Care. 2020; 1-7. https://doi.org/10.1111/ppc.12555

29. Khasawneh AI, Humeidan AA, Alsulaiman JW, et al. Medical students and COVID-19: Knowledge, attitudes, and precautionary measures. a descriptive study from Jordan. Front Public Health. 2020. https://doi.org/10.3389/fpubh.2020.00253

30. Bhagavathula AS, Aldhaleei WA, Rahmani J, et al. Knowledge and perceptions of COVID-19 among health care workers: Crosssectional study. JPHS. 2020; 6(2):e19160. https://doi.org/10.2196/19160

31. Kara E, Demirkan K, Unal S. Knowledge and attitudes of hospital pharmacist about COVID-19. Turk J Pharm Sci. 2020. https://doi. org/10.4274/tjps.galenos.2020.72325 
32. Alhaj AK, Al-Saadi T, Mohammad F, et al. Neurosurgery residents' perspective on COVID-19: Knowledge, readiness, and impact of this pandemic. World Neurosurg. 2020. https://doi.org/10.1016/j.wneu.2020.05.087

33. Nemati M, Ebrahimi B, Nemati F. Assessment of Iranian nurses' knowledge and anxiety toward COVID-19 during the curren out break in Iran. Arch Clin Infect Dis. 2020; e102848. https://doi.org/10.5812/archcid.102848

34. Huh S. How to train health personnel to protect themselves from SARS-CoV-2 (novel coronavirus) infection when caring for a patient or suspected case. J Educ Eval Health Prof. 2020; 17:10. https://doi.org/10.3352/jeehp.2020.17.10

35. Wu SH, Huang CC, Huang SS, et al. Effect of virtual reality training to decreases rates of needle stick/sharp injuries in new-coming medical and nursing interns in Taiwan. J Educ Eval Health Prof. 2020; 17:1. https://doi.org/10.3352/jeehp.2020.17.1

36. Agalar C, Ozturk Engin D. Protective measures for COVID-19 for healthcare providers and laboratory personnel. Turk J Med Sci. 2020; 50:578-584. https://doi.org/10.3906/sag-2004-132

37. Sachan R, Patel ML, Nischal A. Assessment of the knowledge, attitude and practices regarding biomedical waste management amongst the medical and paramedical staff in tertiary health care centre. IJSRP. 2012;2(7): 1-6.

38. Guanche Garcell H. COVID-19. A challenge for healthcare professionals. Rev Habanera Cienc Médi. 2020; 19(2):e_3284_E. 